\title{
CO-TRIMOXAZOLE PREVENTIVE THERAPY REDUCES ACTIVE PULMONARY TUBERCULOSIS RISK IN PEOPLE LIVING WITH HIV/AIDS ON ANTIRETROVIRAL AT WANGAYA HOSPITAL IN DENPASAR, BALI, INDONESIA: A PROSPECTIVE COHORT STUDY
}

\author{
KETUT SURYANA $^{1 *}$, HAMONG SUHARSONO ${ }^{2}$, DWIJO ANARGHA SINDHUGHOSA ${ }^{1}$ \\ ${ }^{1}$ Department of Internal Medicine, Wangaya Hospital in Denpasar, Bali, Indonesia. ${ }^{2}$ Department of Biochemistry, Faculty of Veterinary
} Medicine, Udayana University, Denpasar, Bali, Indonesia. Email: ketutsuryana@gmail.com

Received: 12 January 2019, Revised and Accepted: 13 February 2020

ABSTRACT

Objective: To evaluate whether co-trimoxazole preventive therapy (CPT) and other contributing factors, among people living with HIV/AIDS (PLWHA) on antiretroviral (ARV) are effective to reduce active pulmonary tuberculosis (APT) at Wangaya Hospital, Denpasar, Bali, Indonesia.

Methodology: A prospective cohort study was conducted to evaluate the use of CPT in reducing APT. In this study, 403 PLWHA on ARV 151 participants accepted CPT as the first group and 252 PLWHA refused CPT as the second group. Eight participants among the first group and 48 participants among the second group were confirmed APT. Revisits were scheduled every a month to replenish pills and to confirm APT. The CPT effectiveness, sociodemography and laboratory, and reducing APT risk after prospective cohort entry were analyzed using Chi-square with significant $\mathrm{p}<0.05$. Statistical software package SPSS 15.0 was used for statistical analysis.

Results: Two hundred fifty-one (62.2\%) of the participants were males and 152 (37.8\%) females. Eight (2.0\%) of the first group were confirmed APT and $48(12.0 \%)$ of the second group were confirmed APT ( $\mathrm{p}=0.004)$. In bivariate analysis (Chi-square), we found that sex ( $\mathrm{p}=0.019), \mathrm{smoking}(\mathrm{p}=0.000)$, alcohol consumption $(\mathrm{p}=0.000)$, previous history of tuberculosis $(\mathrm{TB})(\mathrm{p}=0.000)$, and CD4 cell counts $(<69 \mathrm{cell} / \mu \mathrm{L})(\mathrm{p}=0.002)$ were significant APT risk factors. There was significantly less APT risk among the participants who accepted CPT compared with participants refused CPT ( $\mathrm{p}=0.002)$.

Conclusions: This study found that CPT was significantly associated with reduce of APT risk in PLWHA. Furthermore, there were significantly added the preventive effect of CPT; sex, smoking, alcohol consumption, previous history of TB, and CD4 cell counts.

Keywords: Human immunodeficiency virus, Co-trimoxazole preventive therapy, Active pulmonary tuberculosis.

(c) 2020 The Authors. Published by Innovare Academic Sciences Pvt Ltd. This is an open access article under the CC BY license (http://creativecommons. org/licenses/by/4. 0/) DOI: http://dx.doi.org/10.22159/ajpcr.2020.v13i4.36844

\section{INTRODUCTION}

Cotrimoxazole, fixed-dose trimethoprim-sulfamethoxazole, is a low cost and widelyutilized broad-spectrumantibioticused to prevent opportunistic infections in people living with HIV/AIDS (PLWHA) [1-3]. Co-trimoxazole preventive therapy (CPT) has been shown to decrease mortality, morbidity, and hospitalizations among PLWHA [4-6]. It has been recommended as part of the essential care and it supports package for PLWHA at Wangaya Hospital in Denpasar, Bali, Indonesia. It is a broad-spectrum antimicrobial agent active against several aerobics Gram-negative and Gram-positive bacteria, fungi, and protozoa species. In a previous study, mostly clinical isolates of mycobacterium tuberculosis (MTB) from different patients were found to be sensitive to co-trimoxazole. Other studies demonstrated that sulfamethoxazole had an in vitro bacteriostatic activity against MTB [7-9].

Recommendations for co-trimoxazole used in adults PLWHA vary by setting. In the United States and Europe, co-trimoxazole is recommended for PLWHA adults with severe immunosuppression (CD4 counts $<200$ cells $/ \mathrm{mm}^{3}$ ) to decrease mortality, morbidity, and hospitalizations due to opportunistic infections (pulmonary TB). Whether CPT prevents active pulmonary tuberculosis (APT) is still uncertain [10-12].

The aim of this study is to evaluate the reduced of APT risk in PLWHA on antiretroviral (ARV) accepting and refusing CPT at Wangaya Hospital in Denpasar, Bali, Indonesia.

\section{METHODOLOGY}

Study population and design

A prospective cohort study was conducted between January 2015 and December 2018. A total of 403 PLWHA on ARV as participants in this study consisted of 151 participants who accepted CPT and 252 participants refused CPT. Participants routinely visited every month but also incidentally visited for acute illnesses. We evaluated the effectiveness of daily CPT (for 6 months) which reduced the risk of APT in PLWHA on ARV, sociodemography, laboratory (hemoglobin, white blood cells, neutrophil, lymphocyte, neutrophil/lymphocyte ratio, and CD4). They were collected at enrollment after being completed by physicians. We evaluated the APT during 6 months taking $960 \mathrm{mg}$ co-trimoxazole once a day orally [13]. APT was confirmed by a routine diagnostic procedure such as TB screening, Chest X-ray, and laboratory investigations acid-fast bacilli (AFB).

HIV: Human immunodeficiency virus, TB: Tuberculosis, CBC: Cell blood counts, CD4: Cluster differentiation, CXR: Chest X-ray, AFB: Acid-fast bacilli, ATD: Antituberculosis drugs, ART: Antiretroviral therapy, PLWHA: People living with HIV/AIDS, APT: Active pulmonary tuberculosis, CPT: Co-trimoxazole preventive therapy

For all of eligible participants (PLWHA aged $\geq 18$ years) were performed interview, TB screening and giving information on CPT, cell blood count ( $\mathrm{CBC}$ ), and the adherence to the appointed schedule. If there was a suspicion for TB (at least one of the positive symptom screening components), then a radiological and bacteriologic examination (AFB) was done to identify the MTB. If it was confirmed, they were given antituberculosis drugs according to the guideline. Participants who were unconfirmed TB continued to the clinical condition examinations such as nausea/vomiting and co-trimoxazole hypersensitivity. If there was any abnormality, participants were excluded from the study. Participants who were unconfirmed TB or without any clinical abnormality were divided into two groups. The first group: Participants 
who were unconfirmed APT and accepted CPT. The participants who were unconfirmed APT but refused CPT as a second group. During 6 months CPT administration, a TB screening was done for every participants, also for the participants who refused CPT as a control. The participants flowchart in this study is described in Fig. 1.

The independent variables were age, sex, body weight, laboratory result (CBC: Hemoglobin, white blood cells, neutrophil, lymphocyte, and $\mathrm{CD}^{+}$), and WHO clinical stage. Enrolled participants received labeled containers with 60 co-trimoxazole tablets (sulfamethoxazole $400 \mathrm{mg} /$ trimethoprim $80 \mathrm{mg}$ ), were told to take two tablets daily for 30 days, and were given monthly refill appointments. The dependent variables were APT, confirmed by presumptive diagnostic (routine diagnostic procedure). APT were compared between participants accepted CPT and participants refused CPT.

\section{Statistical analysis}

Effectiveness of CPT on APT in PLWHA on ARV after prospective cohort entry was analyzed using Chi-square with $\mathrm{p}<0.05$, it was considered statistically significant. Statistical software package SPSS 15.0 was used for statistical analysis.

\section{Ethical clearance}

Ethical clearance was obtained No: 02/RSUDW/Litbang/2015 from the local ethical committees. We collected data from PLWHA who visited Wangaya Hospital, Merpati Clinic of Denpasar, Bali, Indonesia and completed at least 6 months (this period is considered the time period in which CPT is effective) follow-up from the ethical clearance granted date.

\section{RESULTS}

A prospective cohort study was conducted during January 2015 and December 2018. A total of 403 participants (PLWHA) were enrolled in this study. The mean age (years): $37.31 \pm 9.83$ year, 251 (62.20\%) of the participants are males and $152(37.80 \%)$ females, $311(77.30 \%)$ on secondary education, $132(32.70 \%)$ to be smokers, $153(37.90 \%)$ alcohol consumption, and $165(41.00 \%)$ previous history of TB or presence of a TB patient in the family, the mean of weight $(\mathrm{kg})$ 52.25 \pm 9.04 . Baseline CD4 cell counts: 73.55 \pm 52.51 (Table 1 ).

In the bivariate analysis (Chi-square), we found that male confirmed with APT was statistically significant more frequent than female $(\mathrm{p}=0.019)$ (Table 2).

This study found that male was more likely to develop APT compared with female $(p=0.019)$. A higher proportion of cases was smoking compared to the controls $(\mathrm{p}=0.000)$. Alcohol consumption was more common among the participants with APT than the controls $(p=0.000)$. A previous history of TB or presence of a TB patient in the family was one of the most important risk factors of APT $(\mathrm{p}=0.000)$

To find out the association between CPT and APT among PLWHA, the participants were divided into two groups, the first group: 146 participants received CPT and 257 participants did not receive CPT (second group). In this study, we confirmed APT 8 (2.00\%) among the first group (PLWHA on ARV, received CPT) during the 6 months followup, but $48(12.00 \%)$ among the second group (PLWHA on ARV, refused CPT) were confirmed APT

( $p=0.004$; odds ratio $[O R]=0.252 ; 95 \%$ confidence interval $[C I]=0.094-$ 0.675) (Table 3).

This study found that CPT has a protective effect against TB and it is consistent with other previous studies. CPT has beneficial effects in increasing CD 4 counts as well as reducing APT risk $(\mathrm{p}=0.002)$.

\section{DISCUSSION}

Co-trimoxazole is a broad spectrum antimicrobial agent, synergistically block folic acid microbial synthesis, a vital cofactor in thymidine, and purine manufacture. Sulfamethoxazole is a competitive inhibitor
Table 1: Participant characteristic data (age, sex, weight, hemoglobin, and white blood cell) $(n=403)$

\begin{tabular}{ll}
\hline Variable & n (\%)/mean \pm SD \\
\hline Age (year) & $37.31 \pm 9.83$ \\
Sex & $251(62.20 \%)$ \\
Male & $152(37.80 \%)$ \\
Female & $8(2.00 \%)$ \\
Education level & $47(11.60 \%)$ \\
$\quad$ No formal education & $311(77.30 \%)$ \\
Primary education & $37(9.20 \%)$ \\
Secondary education & $132(32.70 \%)$ \\
Tertiary education & $271(67.30 \%)$ \\
Smoking & $153(37.80 \%)$ \\
Yes & $250(62.20 \%)$ \\
No & \\
Alcohol consumption & \\
Yes & $165(41.00 \%)$ \\
No & $238(59.00 \%)$ \\
Previous history of tuberculosis or presence of a tuberculosis patient \\
in the family & $52.25 \pm 9.04$ \\
Yes & \\
No & $11.78 \pm 2.48$ \\
Weight $(\mathrm{kg})$ & $5.33 \pm 2.40$ \\
Cell blood count & $3.34 \pm 1.98$ \\
Hemoglobin $(\mathrm{g} / \mathrm{dl})$ & $1.01 \pm 0.51$ \\
WBC $(103 / \mu \mathrm{L})$ & $4.49 \pm 5.17$ \\
Neutrophil $(109$ cells/L) & $73.55 \pm 52.51$ \\
Lymphocyte $\left(\mathrm{cells} / \mathrm{mm}{ }^{3}\right)$ & NLR
\end{tabular}

WBC: White blood cells, NLR: Neutrophil lymphocyte ratio, CD4: Cluster differentiation-4, SD: Standard deviation

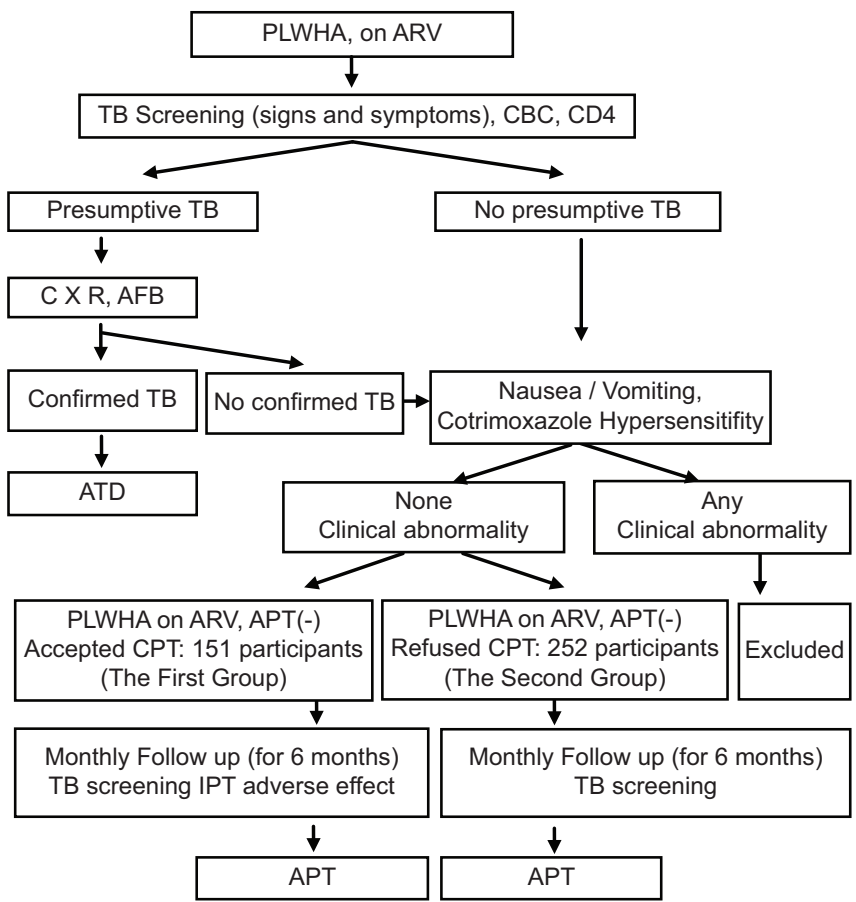

Fig. 1: Participants flowchart.

of dihydrofolic acid synthesis, trimethoprim acts downstream of sulfamethoxazole to inhibit the physiologically active tetrahydrofolic production. The fixed-dose combination (trimethoprimsulfamethoxazole) blockades two sequential enzymes to prevent bactericidal activity $[14,15]$. In a previous study, mostly clinical isolates of MTB from different patients were found sensitive to co-trimoxazole. The other study demonstrated that sulfamethoxazole had in vitro bacteriostatic activity against MTB [7,9,16-18]. 
This study showed significantly association between the factors such as sex, smoking, alcohol consumption, previous history of TB or presence of a TB patient in the family, CD4 cell counts, and CPT with APT. In the other hand, no significant association between the risk factors of APT such as age, weight, hemoglobin, WBC, neutrophil, lymphocyte, and neutrophil-lymphocyte ratio (NLR) with APT (Table 2)

We found that there was a statistically significant association between sex and APT. Male had 2 times higher risk to develop APT compared to female ( $\mathrm{p}=0.019$; OR=2.75; CI 95\%=1.15-6.57). Another study Ku et al. 2019 , found that male was more likely to develop APT compared with female $(\mathrm{p}<0.001)$ [19]. Kibret et al., 2013, reported that males were more likely to develop APT than females $(\mathrm{p}=0.003$; crude odds ratios $[\mathrm{COR}]=1.73 ; 95 \% \mathrm{CI}=1.21-2.46$ ) [20]. However, it is different with Taha et al., 2011, reported that female was statistically significant more frequent than male $(p=0.007)[21]$.

Smoking may cause immune impairment, damages ciliary clearance, and it may increase the APT risk [22-24]. In this study, smoking was identified as a risk factor for APT ( $\mathrm{p}=0.000$; OR=5.944; 95\% CI: 2.74-12.89). Similarly reported by other studies such as Alemu et al., 2016, finding that smoking statistically significant associated with APT $(\mathrm{p}<0.0001$; adjusted odds ratio $[\mathrm{AOR}]=5.47 ; 95 \% \mathrm{CI}=2.26-13.22$ ) [25]. Kibret et al., 2013 , found that smoking was statistically significant associated with increased of APT ( $\mathrm{p}<0.0001$; COR=3.34; 95\% CI=2.087-5.35) [20]. Taha et al., 2011, reported that smoking as a risk factor for APT ( $<<0.001)$ [21].

Long-term alcohol consumption may modulate the immune response, impaired immunity, and it will more likely to develop APT $[26,27]$.
We found that alcohol consumption statistically significant associated with APT ( $\mathrm{p}=0.000 ; \mathrm{OR}=5.214 ; 95 \% \mathrm{CI}=2.374-11.452)$. Another study Alemu et al., 2016, finding that alcohol drinking statistically significant associated with APT ( $\mathrm{p}=0.006$; AOR=2.49; 95\% CI=1.29-4.80) [25]. Kibret et al., 2013, found that alcohol drinking was statistically significant associated with increased of APT $(\mathrm{p}<0.0001$; COR $=2.39$; 95\% CI=1.63-3.52) [20].

This study found that a previous history of TB or TB patient in the family was statistically significant associated with APT ( $p=0.000$; $O R=7.520 ; 95 \%$ CI: 3.137-18.027). Alemu et al., 2016, found that TB patient in the family was statistically significant associated with APT $(p=0.011 ;$ AOR $=2.66$; 95\% CI=1.25-5.66) [25]. In the other hand, Taha et al., 2011, found that a previous history of TB was not associated with APT $(p=0.7)$ [21].

CPT has beneficial effects in enhancing the immunological state (increasing CD4 counts and reducing viral load [VL]) [28]. CPT reduces mortality in HIV infected adults with pulmonary TB $[29,30]$. CD4 counts $<200$ cells $/ \mu \mathrm{L}$ were independent determinants for increased APT. PLWHA with low CD4 counts was more likely to develop APT or other opportunistic infections [31-34]. In this study, the level of CD4 cell counts $<69$ cell $/ \mu \mathrm{L}$ was identified as the risk factor for the development of APT ( $p=0.002$; OR=3.41; 95\% CI: 1.53-7.63). Similarly to other studies, Ku et al. 2019, found that CD4 cell counts 101-200 cell $/ \mu \mathrm{L}$ was identified as the risk factor for the development of APT ( $p<0.001)$ [19]. Alemu et al., 2016, found that CD4 cell counts $<200$ cell/ $\mu \mathrm{L}$ statistically significant associated with APT $(\mathrm{p}<0.0001 ; \mathrm{AOR}=7.22$; 95\% CI=3.39-15.37) [25]. Taha et al., 2011, found that associated with $\operatorname{APT}(\mathrm{p}=0.001)[21]$

Table 2: Association between APT and other variables (sex, age, weight, hemoglobin, WBC neutrophil, lymphocyte, NLR, and CD4) $(n=403)$

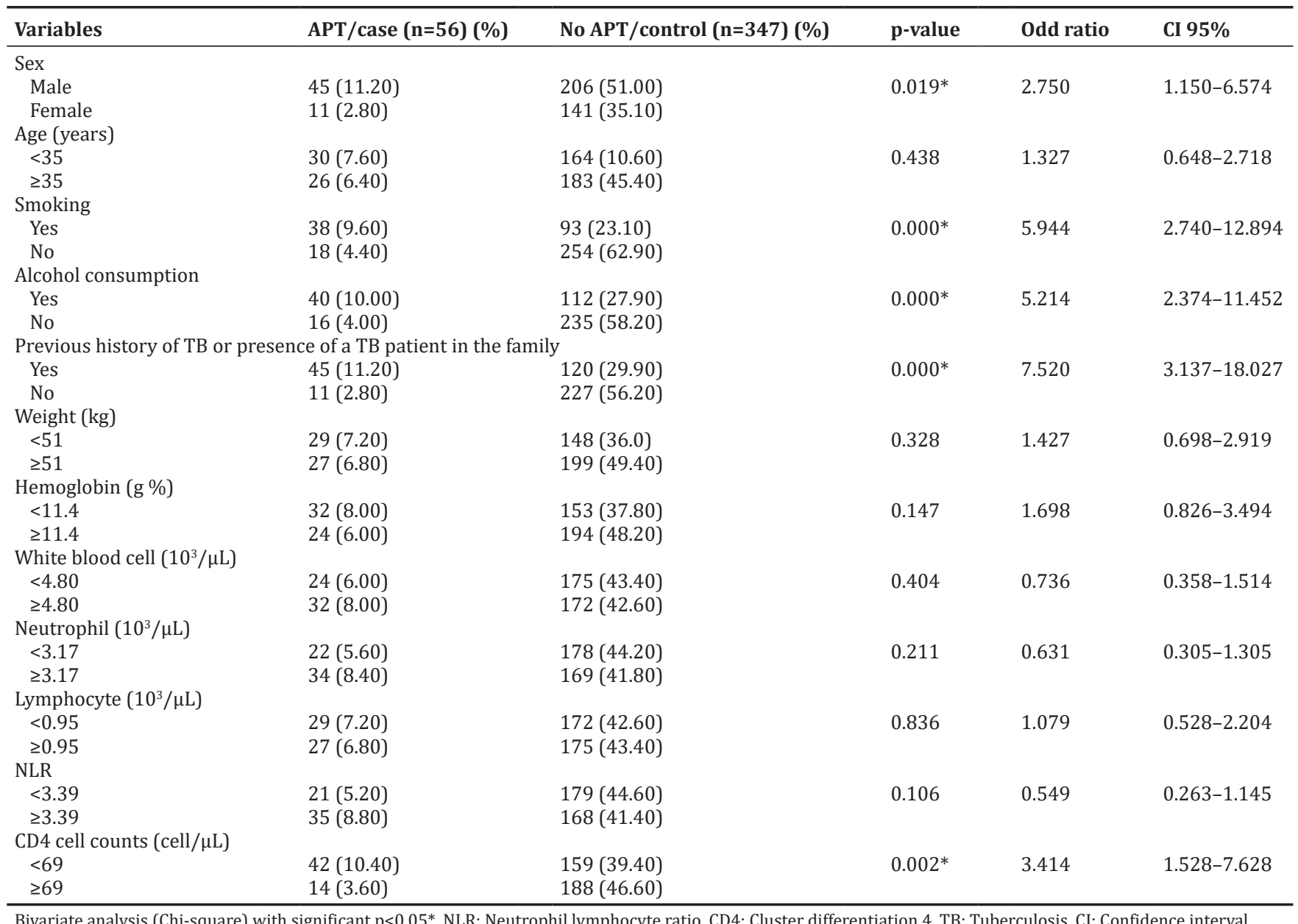


Table 3: Association between co-trimoxazole preventive therapy and active pulmonary tuberculosis (n=403)

\begin{tabular}{|c|c|c|c|c|c|}
\hline Variables & Received CPT (n=146) (\%) & Refused CPT (n=257) (\%) & p-value & Odd ratio & CI 95\% \\
\hline \multicolumn{6}{|c|}{ Active pulmonary tuberculosis } \\
\hline Yes & $8(2.00)$ & $48(12.00)$ & $0.004^{*}$ & 0.252 & $0.094-0.675$ \\
\hline No & $138(34.30)$ & $209(51.80)$ & & & \\
\hline
\end{tabular}

Bivariate analysis (Chi-square) with significant p<0.05*. CPT: Co-trimoxazole preventive therapy, CI: Confidence interval

CPT (sulfamethoxazole) has been found to be active against MTB in vitro [7-9]. Some observational studies suggested CPT decreased the risk of APT in PLWHA and supported a direct antitubercular effect from co-trimoxazole. Therefore, CPT has a protective effect against TB $[3,25,35]$. This study found that daily CPT reduced APT risk among PLWHA on ARV at Wangaya Hospital in Denpasar, Bali, Indonesia. During the 6 months follow-up, there were confirmed $8(2.00 \%)$ APT among the first group (PLWHA, on ARV, accepted CPT) but 48 (12.00\%) among the second group (PLWHA, on ARV, refused CPT). The PLWHA on ARV receiving CPT was less likely to develop APT than PLWHA on ARV did not receive CPT ( $\mathrm{p}=0.004$; OR=0.252; 95\% CI=0.094-0.675). It showed that CPT had a protective effect against TB. This was consistent with other studies. $\mathrm{Ku}$ et al. (2019) found that co-trimoxazole prophylaxis was significantly associated with incident TB diagnosis $(\mathrm{p}<0.001)$. In multivariate analyses, higher VL (1000-4999 copies/ $\mathrm{mL}$ HR $2.18,95 \%$ CI (1.06-4.48), $\mathrm{p}=0.034$ and $\geq 5000$ copies $/ \mathrm{mL}$ HR $2.38,95 \%$ CI (1.63-3.47), p<0.001 were associated with the increased hazard of developing TB compared to $\mathrm{VL}<400$ copies/mL [19]. Alemu et al. (2016) reported that CPT had a beneficial effect in enhancing CD4 cell counts as well as reducing VL and they also found that CPT had a protective effect against TB $(\mathrm{p}<0.0001 ; \mathrm{AOR}=0.32 ; 95 \% \mathrm{CI}=0.19-0.55)$ [25]. Kibret et al., 2013, found that daily CPT reduced APT risk among PLWHA (p<0.0001; COR=0.27; 95\% CI=0.14-0.53) [20].

This study reported that there was no statistically significant association between hemoglobin level, WBC, lymphocyte, neutrophil, and NLR with APT.

\section{CONCLUSIONS}

Our study found that CPT was significantly associated with reduce of APT risk in PLWHA. The other clinical evidence that significantly added the preventive effect of CPT were sex, smoking, alcohol consumption, previous history of TB or presence of a TB patient in the family, and CD4 cell counts.

\section{Limitations of study}

The limitation of this study and the diagnostic of APT cases were confirmed with TB screening, a radiological and bacteriologic examination (AFB) without confirmation with the MTB positive culture results. Recall bias may have affected the accuracy of information related to the substance use in cigarette smoking and alcohol consumption.

\section{ACKNOWLEDGMENT}

We would like to thank the volunteer doctors and all of teamwork of Wangaya HIV Study Group staff for their cooperation during the data collection. We are grateful to Wangaya Hospital Director for the support, I Gede Putu Jarwa Antara for contributing the data collection.

\section{AUTHORS' CONTRIBUTIONS}

Ketut Suryana made substantial contributions to conception and design, acquisition of data, or analysis and interpretation of data; took part in drafting the article or revising it critically for important intellectual content; gave final approval of the version to be published; and agreed to be accountable for all aspects of the work. Hamong Suharsono took part in drafting the article or revising it critically for important intellectual content; gave final approval of the version to be published; and agreed to be accountable for all aspects of the work. Dwijo Anargha Sindhughosarevised it critically for important intellectual content; gave final approval of the version to be published; and agreed to be accountable for all aspects of the work.

\section{CONFLICTS OF INTEREST}

The authors declared that there are no conflicts of interest related to this study.

\section{AUTHORS' FUNDING}

The author(s) received no specific funding for this work.

\section{REFERENCES}

1. Sisay M, Bute D, Edessa D, Mengistu G, Amare F, Gashaw T, et al. Appropriateness of cotrimoxazole prophylactic therapy among HIV/ AIDS patents in public hospitals in Eastern Ethiopia: A retrospective evaluation of clinical practice. Front Pharmacol 2018;9:727.

2. Gebresillassie BM, Gebeyehu MB, Abegaz TM, Erku DA, Mekuria AB, Tadesse YD. Evaluation of cotrimoxazole use as a preventive therapy among patients living with HIV/AIDS in Gondar University referral hospital, Northwestern Ethiophia: A retrospective cross-sectional study. HIV AIDS (Auckl) 2016;8:125-33.

3. Hasse B, Walker AS, Fehr J, Furrer H, Hoffmann M, Battegay M, et al. Co-trimoxazole prophylaxis is associated with reduced risk of incident tuberculosis in participant in the Swiss HIV cohort study. Antimicrob Agents Chemother 2014;58:2363-8.

4. Diriba L, Pharm B, Worku F, Girma T. Evaluation of prophylactic use of cotrimoxazole for people living with HIV/AIDS in Jimma University specialized hospital, Southwest Ethiopia. Ethiop J Health Sci 2008; 18:59-64

5. Polyak CS, Yuhas K, Singa B, Khaemba M, Walson J, Richardson BA, et al. Cotrimoxazole prophylaxis discontinuation among antiretroviral treated HIV-1 infected adults in Kenya: A randomized non inferiority trial. PLoS Med 2016;13:e1001934.

6. Sibanda EL, Weller IV, Hakim JG, Cowan FM. Does trimethoprimsulfamethoxazole prophylaxis for HIV induce bacterial resistance to other antibiotic classes? Results of a systematic review. Clin Infect Dis 2011;52:1184-94.

7. Huang TS, Kunin CM, Yan BS, Chen YS, Lee SSJ, Syu WJ. Susceptibility of Mycobacterium tuberculosis to sulfamethoxazole, trimethoprim and ther combnation over a 12 year period in Taiwan. J Antimicrob Chemother 2012;67:633-7.

8. Ong W, Sievers A, Leslie DE. Mycobacterium tuberculosis and sulfamethoxazole susceptibility. Antimicrob Agents Chemother 2010;54:2748-9.

9. Forgacs P, Wengenack NL, Hall L, Zimmerman SK, Silverman ML, Roberts GD. Tuberculosis and trimethoprim-sulfamethoxazole. Antimicrob Agents Chemother 2009;54:2748-9.

10. Gupta S, Granich R, Hersh B, Lepere P, Samb B. Global policy review of recommendations on cotrimoxazole prophylaxis among people living with HIV. J Int Assoc Provid AIDS Care 2014;13:397-401.

11. Watera C, Todd J, Muwonge R, Whitworth J, Nakiyingi-Miiro J, Brink A, et al. Feasibility and effectiveness of cotrimoxazole prophylaxis for HIV-1 infected adults attending an HIV/AIDS clinic in Uganda. J Acquir Immune Defic Syndr 2006;42:373-8.

12. Date AA, Vitoria M, Granich R, Banda M, Fox MY, Gilks C. Implementation of co-trimoxazole prophylaxis and isoniazid preventive therapy for people living with HIV. Bull World Health Organ 2010;88:253-9.

13. Boeree MJ, Sauvageot D, Banda HT, Harries AD, Zijlstra EE. Efficacy and safety of two dosages of cotrimoxazole as preventive treatment for HIV-infected Malawian adults with new smear-positive tuberculosis. Trop Med Int Health 2005;10:723-33.

14. Macingwana L, Baker B, Ngwane AH, Harper C, Cotton MF, Hesseling A, et al. Sulfamethoxazole enhances the antimycobacterial activity of rifampicin. J Antimicrob Chemother 2012;67:2908-11.

15. Raizada N, Chauhan LS, Babu S, Thakur R, Khera A, Wares DF,et al. Linking HIV-infected TB patients to cotrimoxazole prophylaxis and antiretroviral treatment in India. PLoS One 2009;4:e5999. 
16. Denue BA. Knowledge regarding co-trimoxazolepreventive therapy among patients who are HIV positive in a tertiary health facility, Northeastern Nigeria. Sub Saharan Afr J Med 2018;4:31-6.

17. Church JA, Fitzgerald F, Walker AS, Gibb DM, Prendergast AJ. The expanding role of co-trimoxazole in developing countries. Lancet Infect Dis 2014;15:327-39.

18. Walker AS, Ford D, Gilks CF, Munderi P, Ssali F, Reid A, et al. Daily cotrimoxazole prophylaxis in severely immunosuppressed HIV-infected adults in Africa started on combination antiretroviral therapy: An observational analysis of the DART cohort. Lancet 2010;375:1278-86.

19. Ku SW, Jiamsakul A, Joshi K, Pasayan MK, Widhani A, Chaiwarith R, et al. Cotrimoxazole prophylaxis decreases tuberculosis risk among Asian patients with HIV. J Int AIDS Soc 2019;22:e25264.

20. Kibret KT, Yalew AW, Belaineh BG, Asres MM. Determinant factors associated with occurrence of tuberculosis among adult people living with HIV after antiretroviral treatment initiation in Addis Ababa, Ethiopia: A case control study. PLoS One 2013;8:e64488

21. Taha M, Deribew A, Tessema F, Assegid S, Duchatea L, Colebunders R. Risk factors of active tuberculosis in people living with HIV/AIDS in Southwest Ethiopia: A case control study. Ethiop J health Sci 2011;21:131-9.

22. Horne DJ, Campo M, Ortiz JR, Oren E, Arentz M, Crothers K, et al. Association between smoking and latent tuberculosis in the U.S. population: An analysis of the national health and nutrition examination survey. PLoS One 2012; 7:e49050.

23. Piao WH, Campagnolo D, Dayao C, Lukas RJ, Wu J, Shi FD. Nicotine and inflammatory neurological disorders. Acta Pharmacol Sin 2009;30:715-22.

24. Mehta H, Nazzal K, Sadikot RT. Cigarette smoking and innate immunity. Inflamm Res 2008;57:497-503.

25. Alemu YM, Awoke W, Smiths AW. Determinants for tuberculosis in HIV-infected adults in Northwest Ethiopia: A multicentre case-control study. BMJ Open 2016;6:e009058.
26. Szobo G, Saha B. Alcohol's effect on host defense. Alcohol Res 2012;37:159-70

27. Lonnroth K, Williams BG, Stadlin S, Jaramillo E, Dye C. Alcohol use a risk factor for tuberculosis-a systematic review. BMC Public Health 2008;8:289.

28. Hassani AS, Marston BJ, Kaplan JE. Assessment of the impact of cotrimoxazole prophylaxis on key outcomes among HIV-infected adults in low-and middle-income countries: A systematic review. J Acquir Immune Defic Syndr 2015;68 Suppl 3:S257-69.

29. Nunn AJ, Mwaba P, Chintu C, Mwinga A, Darbyshire JH, Zumla A. Role of co-trimoxazole prophylaxis in reducing mortality in HIV infected adults being treated for tuberculosis: Randomized clinical trial. BMJ 2008;337:a257.

30. Hoffman CJ, Chaisson RE, Martinson NA. Cotrimoxazole prophylaxis and tuberculosis risk among people living with HIV. PLoS One 2014;9:e83750.

31. Djergjii M, Bushati J, Harxhi A, Hafizi H, Pipero P. Tuberculosis in HIV/AIDS patients. Adv Tech Clin Microbiol 2017;1:16.

32. Giri PA, Desphande JD, Phalke DB. Prevalence of pulmonary tuberculosis among HIV positive patients attending antiretroviral therapy clinic. N Am J Med Sci 2013;5:367-70.

33. Skogmar S, Schon T, Balcha TT, Jemal ZH, Tibesso G, Björk J, et al. CD4 cell levels during treatment for tuberculosis (TB) in Ethiopian adults and clinical markers associated with CD4 lymphocytopenia. PLoS One 2013;8:e83270.

34. Tariku Y, Yaya Y, Jerene D, Tamiso A. Incidence of opportunistic infections among adult HIV positive people receiving co-trimoxazole prophylaxis. Int J Public Health Sci 2015;4:172-9.

35. Vilcheze C, Jacobs WR Jr. The combination of sulfamethoxazole, trimethoprim, and isoniazid or rifampin is bactericidal and prevents the emergence of drug resistance in mycobacterium tuberculosis. Antimicrob Agents Chemother 2012;56:5142-8 